\title{
Stress-strain state analysis of structures based on the monitoring data
}

\author{
Dmitriy Sidorov ${ }^{1}$, and Vladimir Dorozhinskiy ${ }^{1, *}$ \\ ${ }^{1}$ Moscow State University of Civil Engineering, Yaroslavskoe shosse, 26, Moscow, 129337, Russia
}

\begin{abstract}
Advances in construction technology result in increased complexity and multi-functionality of modern buildings and structures. This is especially true for unique structures with large spans and heights. Based on the current standards, such structures must be monitored as well as the stress-strain state (SSS) of supporting structures. In addition, the SSS must be continuously checked during operation. Indeed, facilities of higher complexity are more prone to errors or discrepancies, which can reduce the reliability of some structures as well as the whole system. This can be caused by human factor, variability of external and internal forces and impacts, specifics of erection and installation, and many other reasons. Therefore, unique buildings and structures must be built with monitoring systems or operated under routine inspection. This way we can determine if the behavior of the erected structure complies with the standards and regulations.
\end{abstract}

\section{Problem setting}

Taking measurements and collecting data for all support structures is a very timeconsuming and expensive challenge. For better results, it is more practical to select the structural points for parameter monitoring (such as stress, strain, travel, acceleration) in the most stressed and critical elements. For example, let us look at the support structures of the soccer stadium cover in Saint Petersburg. It is made of steel members and designed as a low-pitched dome. Main dimensions of the dome: outer diameter $=295.90 \mathrm{~m}$; curvature of outside roof surface $=725.00 \mathrm{~m}$; span diameter over the field $=150.00 \mathrm{~m}$. The cover consists of a fixed roof and two sliding sections guided by the traveling truss (Figure 1).

The cover is supported by the stand bowl at the top and additionally suspended on 8 inclined piers by cable stays: 5 cable stays per pier. $108 \mathrm{~m}$ long piers are designed as steel tubes of variable section (diameter at the support is $1.63 \mathrm{~m}$, diameter in the middle is $3 \mathrm{~m}$, tube wall thickness is $16-50 \mathrm{~mm}$ ) with stiffeners on the inside (Figure 2).

\footnotetext{
* Corresponding author: dorozhinski@mail.ru
} 

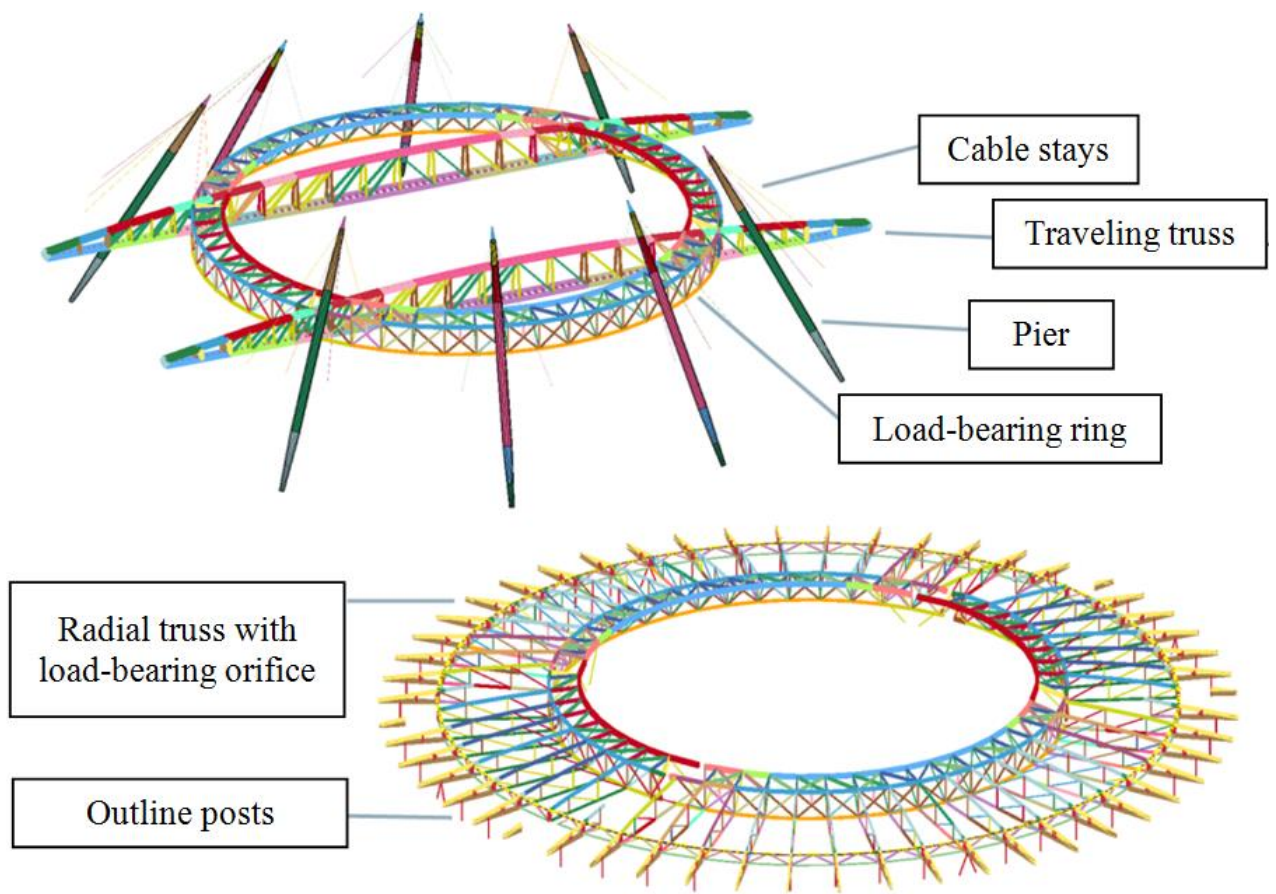

Fig. 1. Fixed roof support structures.

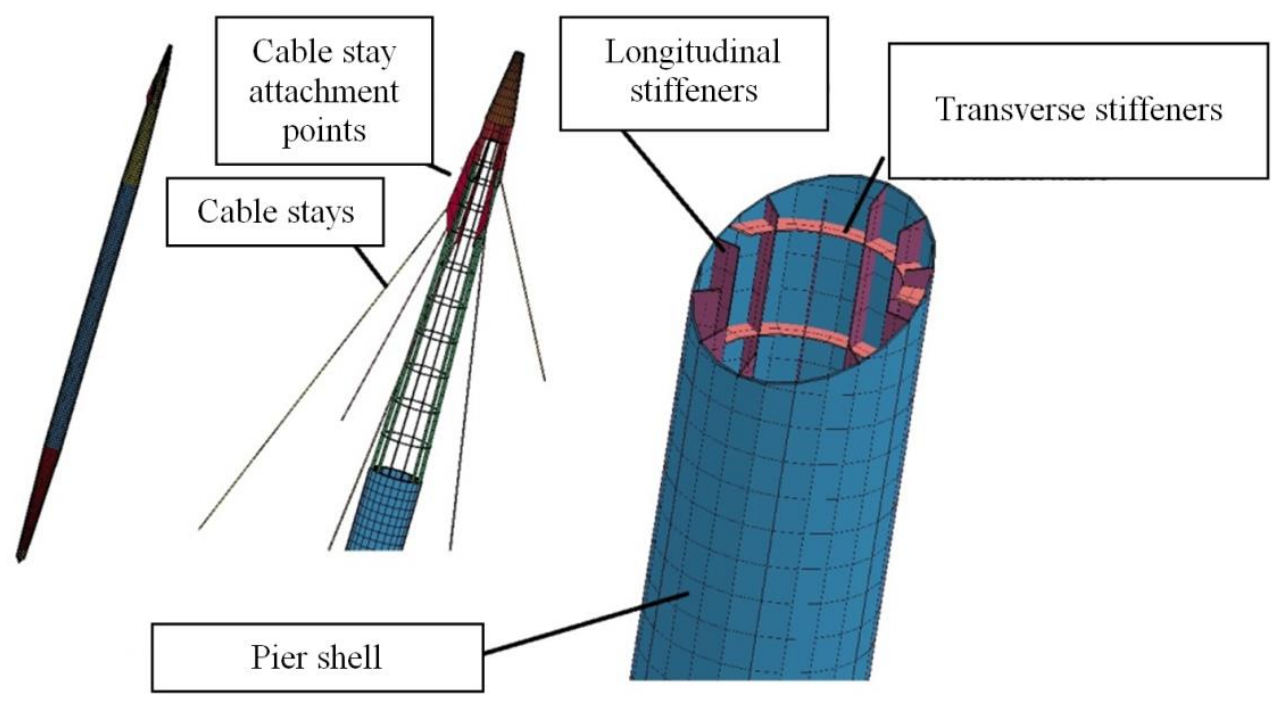

Fig. 2. Pier structural design.

The inclined pier acts as a beam column and is one of the critical elements of the structure. The axial force applied by the design loads of the pier exceeds 6,000 tons and additionally creates a bending moment because of the geometrical nonlinearity of the pier. Experts of the NRU MGSU have studied these structures to determine the actual travel. 


\section{Main results}

The actual spatial position of the structure was determined using land surveying and laser scanning [1-4]. Figure 3 shows a cloud of points collected by the laser scan. The main advantages of the laser scanning technology are:

- high detail of the scanned objects;

- survey of hard-to-reach and complex objects;

- minimization of performance error due to automation;

- design of plans using a point model instead of discrete measurements.
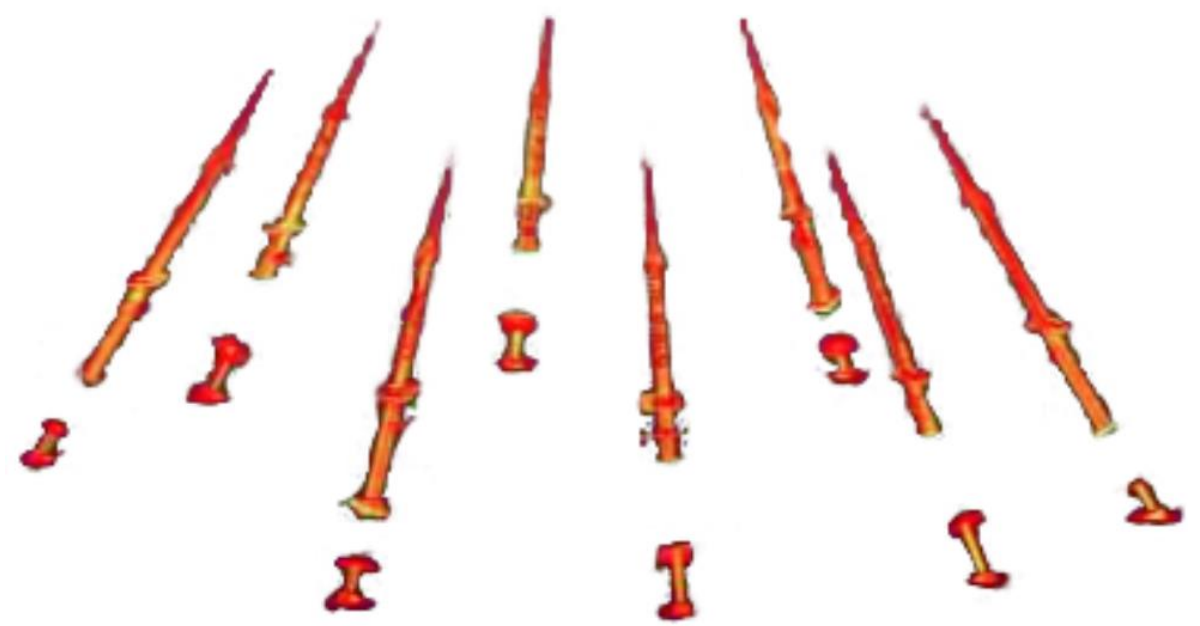

Fig. 3. Point model of the laser scan.

Figure 4 shows a sample arrangement used to determine the deflection by a direct surveying method.

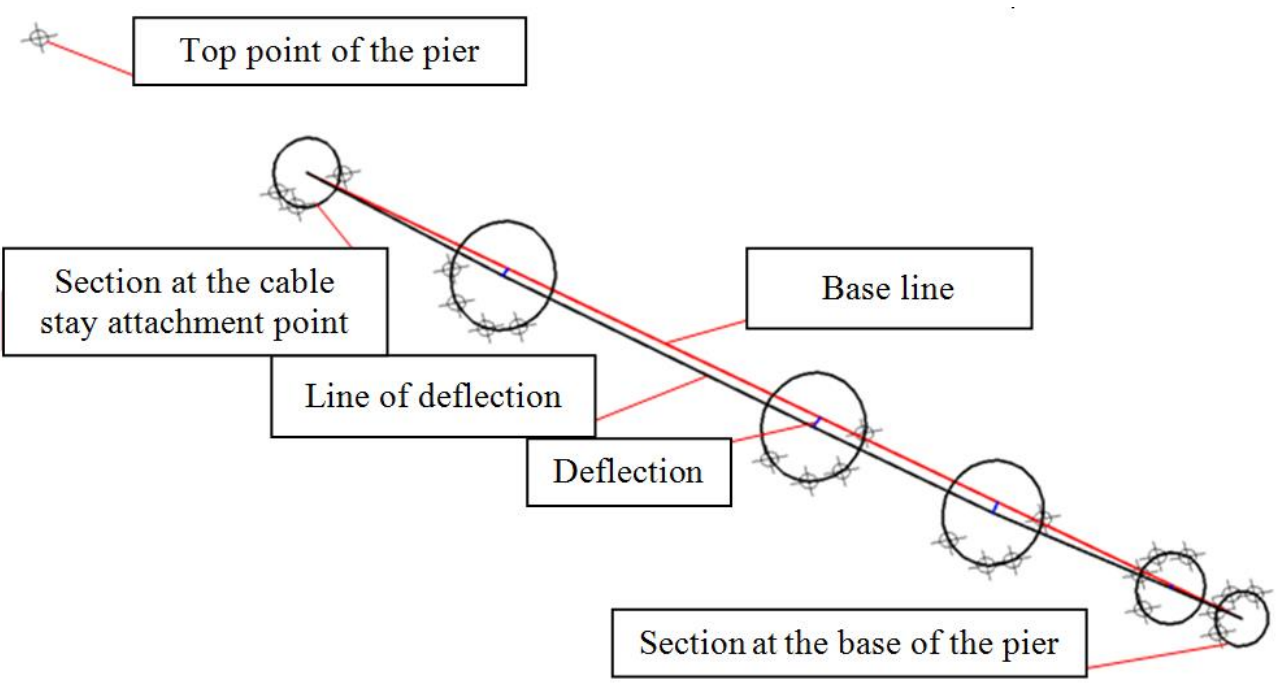

Fig. 4. Pier deflection calculation using the surveying method.

Table 1 shows the results of processing the collected data. Note that the data were collected without snow load and for both methods are almost identical. 
Table 1. Pier deflection.

\begin{tabular}{|c|c|c|}
\hline Pier number & Location of deflection & Deflection value, $\mathrm{mm}$ \\
\hline 1 & Middle of the pier & 299 \\
\hline 2 & Middle of the pier & 320 \\
\hline \multirow{2}{*}{3} & $1 / 4$ of the pier height taken from the base & 245 \\
\cline { 2 - 3 } & Middle of the pier & 223 \\
\hline 4 & Middle of the pier & 276 \\
\hline 5 & Middle of the pier & 276 \\
\hline 6 & Middle of the pier & 221 \\
\hline 7 & Middle of the pier & 248 \\
\hline 8 & Middle of the pier & 242 \\
\hline
\end{tabular}

Next, verification was made to check the stress-strain state of the structure using the ANSYS, LS-DYNA software suite, which considers the physical and geometric nonlinearities. Problems were solved using explicit and implicit integration methods [5].

When analyzing the strain of piers, two models were used: core and shell. According to the second model, the cylindrical and conical shell elements of the pier were simulated by the spatial elements of the shell. The shell model of piers included longitudinal and transverse stiffeners.

Based on the results of a comparative analysis of design deflections of piers and deflection values collected by monitoring, it is safe to conclude that the actual bending stiffness of piers is reduced, and the deflections are increased. This may be due to the increased strain capacity of the structure near the flange connections along the length of the pier (the pier consists of eleven blocks) as well as with the specifics of erection (lack of fit).

Below are some of the results of the study. Calculation results for piers are given for the design and actual reduced stiffness of piers.

Figures 5 and 6 show the deflection and bending moment trends within the pier plane given the design stiffness against load applied step by step. The full design load is reached at step 6. Figure 7 shows the isofields of the stress intensity at a full design load. Explicit and implicit calculation methods show a good compliance of the results.

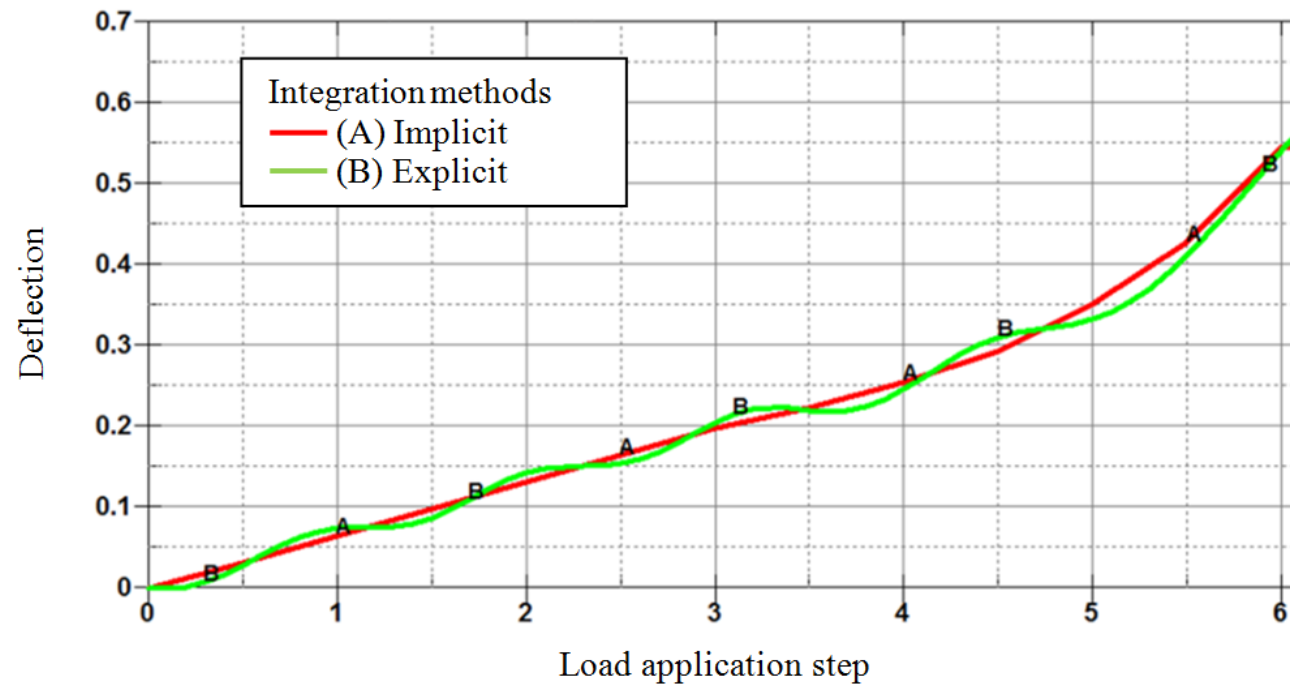

Fig. 5. Pier deflection at a design stiffness, $m$. 


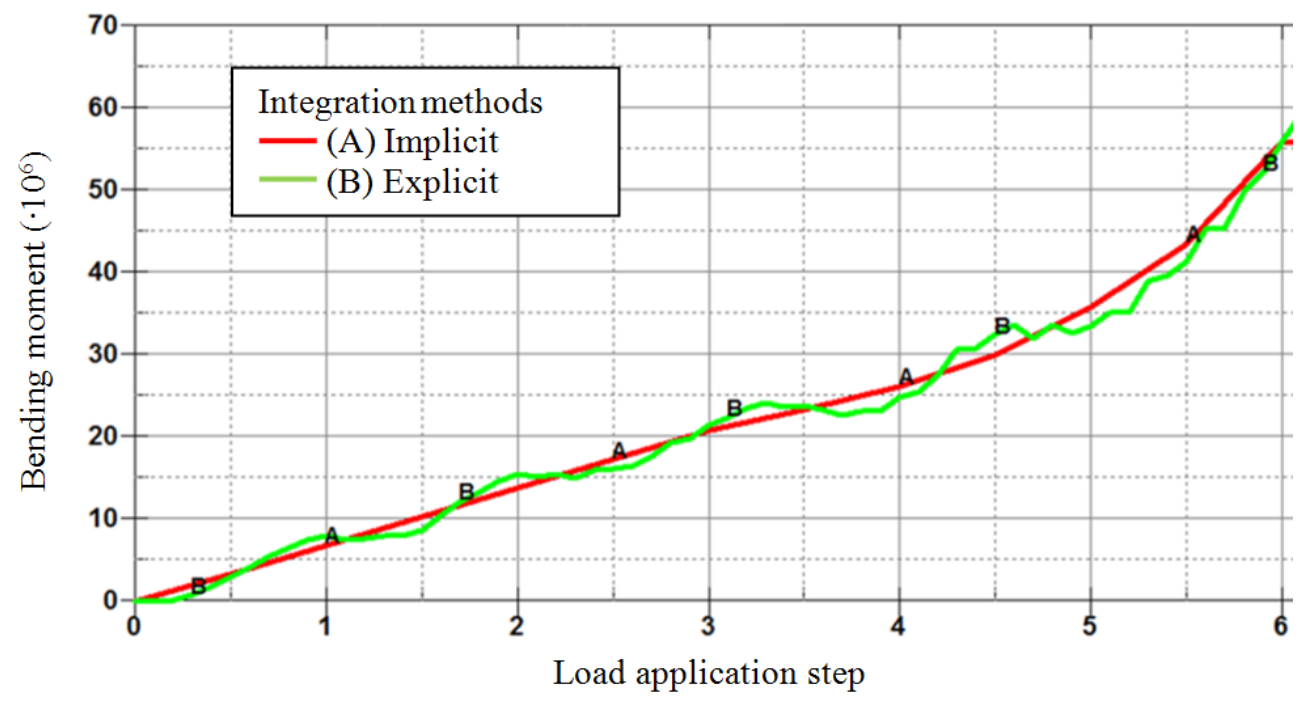

Fig. 6. Bending moment at a design stiffness, $N \cdot m$. LS-DYNA keyword deck by LS-PrePost
Time $=6$

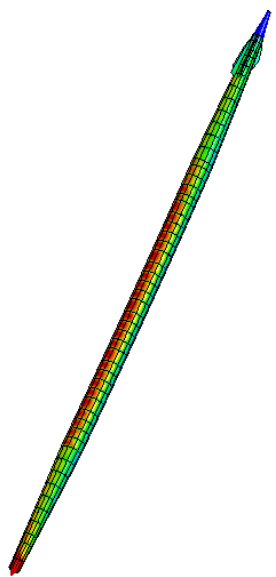

Effective Stress (v-m) $3.800 \mathrm{e}+08$

Fig. 7. Stress intensity at a design stiffness, Pa.

Figures 8 and 9 show the deflection and bending moment curves for the pier plane at an actual reduced stiffness.

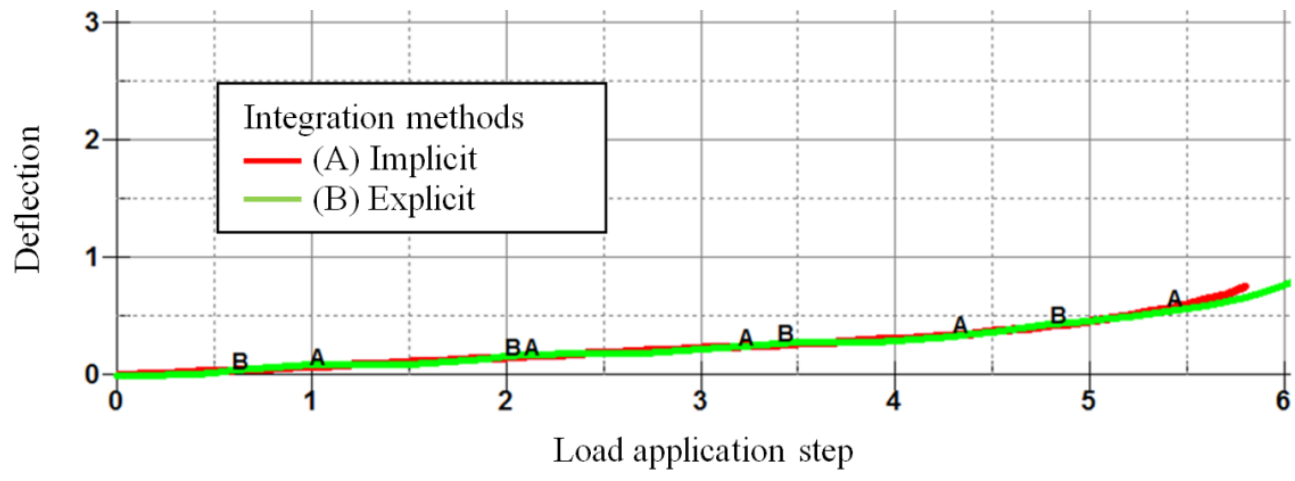

Fig. 8. Pier deflection at a reduced stiffness, m. 


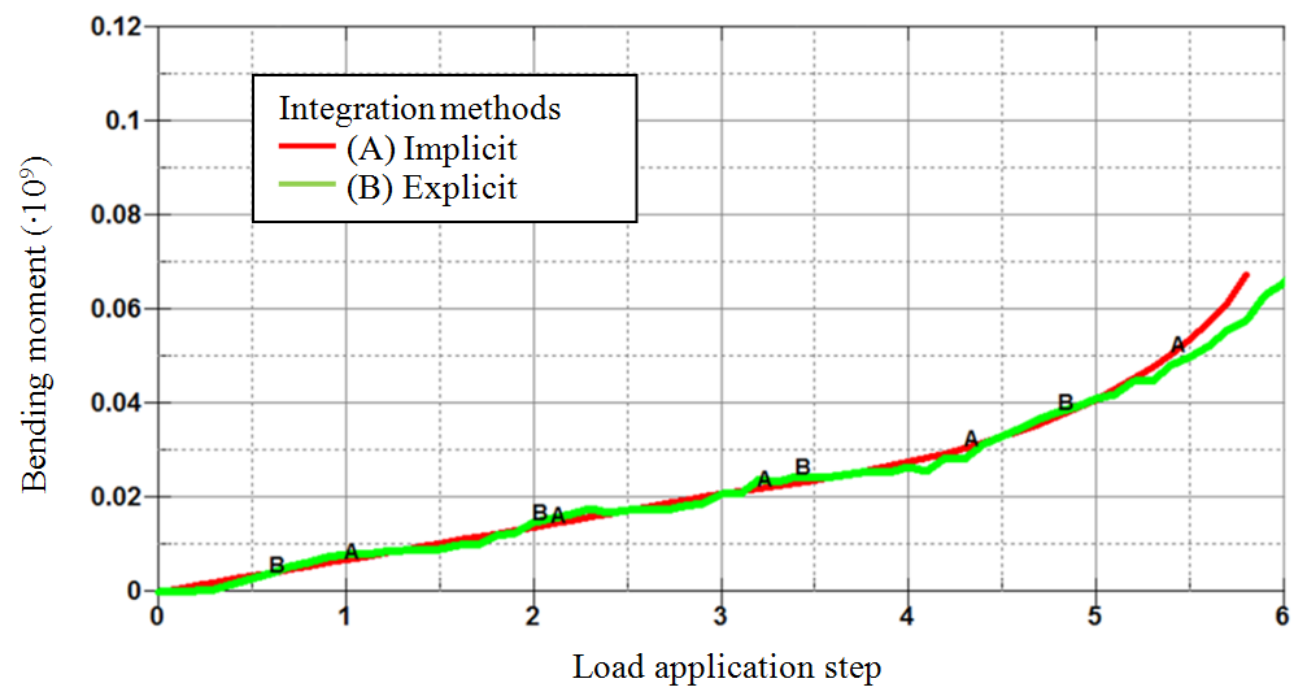

Fig. 9. Bending moment at a reduced stiffness, $N \cdot m$.

\section{Conclusions}

After analyzing the resulting data, the following conclusions can be made:

1. Deflection of inclined piers measured by monitoring exceeds the design values. The calculation model was verified with the parameters of pier stiffness identified.

2. Considering the actual reduced stiffness, the deflection and bending moment increased by $40 \%$ and $20 \%$ respectively, which is significant for the stress-strain state of the structure. 3 . Unique buildings and structures should be operated under mandatory monitoring of the stress-strain state and supporting calculations. It is advisable to introduce an automatic system for real-time monitoring of the necessary parameters. The points of the structure used for monitoring of parameters must be in the key support structures, where the basic and specific combinations of loads are determined by calculation. Supporting calculations must include verification of the calculation model and identification of design parameters. This will open a possibility to guaranty reliability and trouble-free operation of both individual supporting elements and the entire structure.

This study was performed with the support of the RF Ministry of Education and Science, grant \#7.1524.2017/4.6.

\section{References}

1. D. Hui, L. Hongyang, S. Cheng, J. Yiping. Journal of Surveying Engineering, 143 (4), No. 06017001 (2017)

2. W. Lu, J. Teng, Q. Zhou, Q. Peng. Sensors, 18 (2), № 419 (2018)

3. M. Liu, Q.-S. Li, S.-H. Huang, F. Shi, F. Chen. Journal of Wind Engineering and Industrial Aerodynamics, 179, 39-57 (2018)

4. R. Liu, X. Li, S. Xue, M. Mollaert, J. Ye. Earthquake Engineering and Engineering Vibration, 16 (3), 557-569 (2017)

5. O. Mkrtychev, G. Dzhinchvelashvili, M. Busalova. MATEC Web of Conference, 86, UNSP 01018 (2016) 